\title{
Association of HLA-G 3' UTR polymorphism and expression with the progression of cervical lesions in human papillomavirus 18 infections
}

\author{
Hui-Hui Xu ${ }^{1,2}$, Xia Zhang ${ }^{3}$, Hai-Hong Zheng ${ }^{4}$, Qiu-Yue Han ${ }^{3}$, Ai-Fen Lin ${ }^{3}$ and Wei-Hua Yan ${ }^{1,2^{*}}$ (D)
}

\begin{abstract}
Background: Human leukocyte antigen (HLA)-G is an immune checkpoint molecule, which expression in cervical cancer cells enables them to escape immunosurveillance. To date, limited information has been published on the association of HLA-G genetic background in malignant cells with levels of HLA-G expression and the clinical outcome of patients.

Methods: We investigated the influence of the HLA-G 14 bp In/Del (rs66554220) and + 3142C/G (rs1063320) polymorphisms in 130 cases of HPV16 infection, 130 cases of HPV18 infection and 185 age-matched, unrelated, HPV-negative, and cytologically normal Chinese Han women. Case-matched cervical biopsy tissues were evaluated by immunohistochemistry.

Results: Our findings show that the frequency of alleles, $14 \mathrm{bp}$ In (38.5\% vs $29.2 \%, \mathrm{OR}=1.52, P<0.05)$ and $+3142 \mathrm{G}$ (72.7\% vs $57.0 \%, O R=2.01, P<0.05$ ), were significantly increased in the HPV18-infected group compared with the control group. The HLA-G polymorphisms (alleles $14 \mathrm{bp}$ In and $+3142 \mathrm{G}$ ) are also associated with the progression of HPV18-related cervical lesions. Moreover, HLA-G expression increased from CIN1 to CIN2/3 lesions and was highest in patients with adenocarcinoma; however, a significant association between these characteristics and the HLA-G polymorphisms was not observed.

Conclusion: Our results support that the HLA-G 14 bp In and + 3142G alleles are risk factors for HPV18 infections and influence the progression of HPV18-related cervical lesions. This suggests that HLA-G-driven immune mechanisms play an important role in cervical carcinogenesis.
\end{abstract}

Keywords: Human leukocyte antigen-G, Polymorphism, Expression, Human papillomavirus 18, Precancerous cervical lesions, Cervical cancer

\section{Introduction}

Cervical cancer is the second most common cancer, as well as the third leading cause of cancer mortality among women, worldwide [1]. Among all possible etiological factors, an infection with high-risk human papillomavirus (hrHPV) is necessary for the development of high-grade cervical intraepithelial neoplasia $(\mathrm{CIN} 2 / 3)$ and invasive

\footnotetext{
* Correspondence: yanwhcom@yahoo.com

'Medical Research Center, Taizhou Hospital of Zhejiang Province, Wenzhou Medical University, Linhai, Zhejiang, China

'Laboratory of Gynecologic Oncology, Taizhou Hospital of Zhejiang Province, Wenzhou Medical University, Linhai, Zhejiang, China

Full list of author information is available at the end of the article
}

cervical cancer (ICC), but it is not sufficient for these conditions [2]. HPV16 and HPV18 are the two most carcinogenic HPV genotypes, accounting for $55-60 \%$ and 10 $15 \%$ of ICC worldwide, respectively. However, only a small proportion of women infected with HPV develop CIN2/3 (10\% of HPV infections) and cervical cancer (less than $1 \%$ of HPV infections); in most women, the infection regresses spontaneously. Evidence suggests that other factors, including the immune system and genetics of the host, as well as the viral genotype, appear to play a role in the development of cervical cancer [3].

(c) The Author(s). 2018 Open Access This article is distributed under the terms of the Creative Commons Attribution 4.0 International License (http://creativecommons.org/licenses/by/4.0/), which permits unrestricted use, distribution, and 
Human leukocyte antigen-G (HLA-G) is a non-classical HLA class I molecule with well-characterized immunomodulatory activities, including downregulation of the innate and adaptive immune responses and the induction of tolerance. HLA-G interacts with the inhibitory receptors, immunoglobulin-like transcript (ILT)-2, ILT-4, and KIR 2DL4 through several mechanisms. These mechanisms include preventing the cytotoxic activity of natural killer and cytotoxic $\mathrm{T}$ cells, $\mathrm{CD}_{4}^{+} \mathrm{T}$ cell alloproliferative responses and the maturation and function of antigen-presenting cells. Additionally, HLA-G may exert long-term tolerogenic effects by modulating cytokine production and inducing immune regulatory cells [4]. Under various pathological conditions, HLA-G expression has been reported to be involved in tumor cell immune escape, transplantation, viral infection, inflammation, and autoimmune diseases [5]. HLA-G mRNA can be generated in seven different isoforms due to the alternative splicing activity of its primary transcripts, where HLA-G1, -G2, -G3, and HLA-G4 are membrane-bound, and HLA-G5, -G6, and HLA-G7 are soluble isoforms. HLA-G exhibits low polymorphism levels, with only 56 alleles and 18 proteins described so far (http:// hla.alleles.org/nomenclature/stats.html). The $14 \mathrm{bp} \mathrm{In/Del}$ polymorphism (rs66554220) is located at the $3^{\prime}$ untranslated region (3'UTR) and has been proven to influence the stability and splicing patterns of HLA-G mRNA, which is associated with HLA-G expression status $[6,7]$. The SNP, $+3142 \mathrm{C} / \mathrm{G}$ (rs1063320), which is known to be within a predicted binding site for microRNAs, is thought to be important in facilitating HLA-G expression through post-tran scriptional regulation [8].

Our previous findings indicated that HLA-G expression was associated with disease progression in cervical cancer [9]. Recently, we reported that HLA-G 3'UTR polymorphisms were genetic susceptibility factors for active HPV infections, especially for high-risk HPV infections [10]. Whether the expression of HLA-G depends on the HPV type, the genetic background of patients or both is a question that has not yet been answered. The aim of this study was to perform a paired analysis of the relationship between HLA-G 3' UTR polymorphisms (14 bp In/Del and $+3142 \mathrm{C} / \mathrm{G})$ and HLA-G expression in patients with HPV16 or HPV18 infections (stratified according to lesion severity).

\section{Materials and methods}

\section{Ethics statement}

This study was approved by the Institutional Medical Ethics Review Board of Taizhou Hospital in Zhejiang Province. Biosamples were provided by the Tissue Bank of Taizhou Hospital in Zhejiang Province (National human genetic resources sharing service platform of China 2005DKA21300). All of the participants were Chinese Han women, who provided written, informed consent to participate in the study. Confidentiality was ensured during the data collection process, which was completed by Taizhou Hospital; data were analyzed anonymously.

\section{Study design and subjects}

The subjects of this study were women who underwent cervical cancer screening in the gynecological clinic at Taizhou Hospital of Zhejiang Province. Of the 17,669 women, 3210 (18.2\%) were hrHPV positive. In the hrHPV group, HPV52 was the most prevalent genotype (871, 27.1\%), followed by HPV16 (545, 17.0\%), HPV58 (483, 15.0\%), HPV39 (278, 8.7\%), HPV18 (264, 8.2\%), and HPV56 (257, 8.0\%). These results were previously reported in our TZHPV study [11]. The inclusion criteria of this study encompassed the following: women with an HPV16 or HPV18 single infection, no current pregnancies, and no history of total uterus or cervix resection.

A total of 445 women between the ages of 18 to 72 years were recruited and included 130 cases of HPV16 infection, 130 cases of HPV18 infection and 185 cases involving those who were HPV negative and cytologically normal. According to the 2012 ASCCP consensus guidelines for the abnormal cervical cancer screening, women with HPV16 or HPV18 positive should be referred directly to colposcopy. Finally, 153 case-matched cervical biopsy tissues were collected from patients harboring HPV16 or HPV18 infections. The clinical characteristics of the study population are shown in Table 1. Cervical exfoliated cell sample (obtained through cervical scraping) was collected from all eligible women. Biopsy tissues were sectioned and histologically evaluated following hematoxylin and eosin staining (H\&E) by two experienced histopathologists, in a double-blind protocol.

\section{HPV genotyping and sequencing}

HPV genotyping was performed according to a previously described protocol, using a commercial detection kit purchased from Tellgen Life Science (Shanghai, China), which was approved by the China Food and Drug Administration (CFDA Certified NO. (2014): 3400847) [11]. Briefly, the protocol is based on the GP5 +/bioGP6 + -PCR, and involves using sets of biotinylated amplimers and a multiplex human papillomavirus genotyping (MPG) methods with bead-based Luminex suspension array technology $[11,12]$, which is able to simultaneously identify 14 high-risk HPV types, 12 low-risk HPV types and $\beta$-globin gene (internal control).

The conserved $L 1$ regions of HPV 16 and HPV 18 isolates were amplified from either HPV16 or HPV18-positive samples using consensus primers MY09/11(455 bp). The PCR reactions were pre-heated for $5 \mathrm{~min}$ at $95^{\circ} \mathrm{C}$, followed by 40 repeated cycles of $94{ }^{\circ} \mathrm{C}$ for $30 \mathrm{~s}, 55^{\circ} \mathrm{C}$ for $30 \mathrm{~s}, 72^{\circ} \mathrm{C}$ for $30 \mathrm{~s}$, and a final extension step at $72^{\circ} \mathrm{C}$ for $7 \mathrm{~min}$. The PCR products were visualized using $1.5 \%$ agarose gels and 
Table 1 Study Participant Characteristics

\begin{tabular}{|c|c|c|c|}
\hline Characteristic & $\begin{array}{l}\text { Controls } \\
(n=185)\end{array}$ & $\begin{array}{l}\text { HPV16 group } \\
(n=130)\end{array}$ & $\begin{array}{l}\text { HPV18 group } \\
(n=130)\end{array}$ \\
\hline \multicolumn{4}{|c|}{ Age at screening, years } \\
\hline Median & $40.8 \pm 8.0$ & $41.3 \pm 10.0$ & $41.0 \pm 9.8$ \\
\hline Range & $18-69$ & $20-71$ & $21-72$ \\
\hline \multicolumn{4}{|l|}{ HPV status } \\
\hline HPV negative & 185 & 0 & 0 \\
\hline HPV16 positive & 0 & 130 & 0 \\
\hline HPV18 positive & 0 & 0 & 130 \\
\hline \multicolumn{4}{|l|}{ Cytology } \\
\hline NILM & 185 & $40(52.6)$ & $89(88.1)$ \\
\hline ASCUS & 0 & $10(13.2)$ & $5(5.0)$ \\
\hline $\mathrm{ASC}-\mathrm{H}$ & 0 & $11(14.5)$ & $4(4.0)$ \\
\hline LSIL & 0 & $12(15.8)$ & $3(3.0)$ \\
\hline HSIL & 0 & $3(3.9)$ & $0(0.0)$ \\
\hline \multicolumn{4}{|l|}{ Histology diagnosis } \\
\hline Normal/Cervicitis & - & $24(27.9)$ & $50(74.6)$ \\
\hline CIN1 & - & 10(11.6) & 11(16.4) \\
\hline CIN2 & - & $15(17.4)$ & $1(1.5)$ \\
\hline CIN3 & - & $31(36.0)$ & $3(4.5)$ \\
\hline SCC & - & $6(7.0)$ & $0(0.0)$ \\
\hline$A D C$ & - & $0(0.0)$ & $2(3.0)$ \\
\hline
\end{tabular}

Abbreviations, HPV human papillomavirus, NILM negative for intraepithelial lesion or malignancy, ASCUS atypical squamous cells of undetermined significance, ASC-H atypical squamous cells and cannot exclude high-grade squamous intraepithelial lesions, LSIL low-grade squamous intraepithelial lesions, HSIL high-grade squamous intraepithelial lesions, CIN cervical intraepithelial neoplasia, SCC squamous cell carcinoma, $A D C$ adenocarcinoma

were then sent to the Beijing Genomics Institute for DNA sequencing (ABI 3730, Applied Biosystems, Foster City, CA, USA).

\section{HLA-G genotyping}

Genomic DNA was extracted using a QIAGEN kit (QIAGEN, Grand Island, NY), according to the manufacturer's recommendations. The PCR analyses of the HLA-G $14 \mathrm{bp} \quad \mathrm{In} / \mathrm{Del}$ and $+3142 \mathrm{C} / \mathrm{G}$ polymorphisms were performed using a standard protocol, as previously described [10]. Briefly, for each sample, a double PCR reaction was performed to verify the presence of the alleles $+3142 \mathrm{C}$ or $+3142 \mathrm{G}$. Moreover, we performed another PCR reaction with the primers, $14 \mathrm{~F}-5^{\prime}$-GTTG AGGGGAACAGG GGACAT-3' and 14R-5'-AAAG TTCTCATGTCTTCCATTT-3', to confirm the $14 \mathrm{bp}$ In/Del polymorphism in each sample. Globin signals were amplified in parallel with each sample, and used as internal controls. The amplified fragments were visualized by $10 \%$, non-denaturing, polyacrylamide gel electrophoresis (PAGE), stained with ethidium bromide and scored by three different observers. The PCR products were confirmed through sequencing (ABI 3730, Applied Biosystems, Foster City, CA, USA).

\section{Immunohistochemistry and staining evaluation}

Immunohistochemistry (IHC) was performed following a standard protocol, as previously reported [9]. In the staining procedure, the guidelines of the Dako EnVision kit (Dako, Glostrup, Denmark), were strictly followed. The monoclonal antibody, 4H84 (able to detect all HLA-G isoforms), was purchased from Exbio (Prague, Czech Republic). The percentage of HLA-G expression was considered to be positive at $>5 \%$ and negative at $\leq 5 \%$ HLA-G staining, in cervical lesions. Cells were assigned a value (positive or negative) based on the presence or absence of HLA-G staining, irrespective of staining intensity [13].

\section{Statistical analysis}

A statistical analysis was performed using SPSS 16.0 software (SPSS Inc., Chicago, IL). Chi-squared and Fisher's exact tests were used to compare the $H L A-G$ allelic and genotypic frequencies of controls and patients. They were also used to evaluate the relative CIN2 or CIN2+ (more severe) risk associated with HPV genotypes, odds ratios (OR) and the relative 95\% confidence interval (CI). An analysis of covariance (ANCOVA) was used to adjust the mean age between the HPV18 subgroups. $P$ values were two-sided, and the results were considered statistically significant if the $P$ value was 0.05 or less.

\section{Results}

\section{Characteristics of the population}

One hundred and thirty patients infected with HPV16 were successfully sequenced for the $L 1$ gene and classified as the HPV16 group, 130 patients infected with HPV18 (confirmed by sequencing for the $L 1$ gene) were classified as the HPV18 group, and 185 women without an HPV infection and exhibiting normal cervical cytology, were classified as the control group. Eighty-six HPV16-infected patients were diagnosed via cervical biopsy, including 24 normal cases/cervicitis (27.9\%), 10 CIN1 (11.6\%), and 52 CIN2+ (60.5\%). Sixty-seven HPV18-infected patients were diagnosed via cervical biopsy, including 50 normal cases/ cervicitis (74.6\%), 11 CIN1 cases (16.4\%), and 6 CIN2+ cases $(9.0 \%)$. Compared with HPV18, the OR for CIN2+ in HPV16-infected patients was 15.5 (95\%CI, 6.8-35.6, $P$ $<0.001)$, which indicated that women infected with HPV16 may be at an increased risk for CIN1 lesions. These lesions may progress to CIN2 or a more deleterious lesion. HPV18 may have a lower oncogenic potential or require a longer period of time to become carcinogenic [14]. However, HPV18 has a greater tendency to cause adenocarcinoma (ADC) in comparison to HPV16. 


\section{HLA-G 3' UTR polymorphism association with HPV18 infections}

In this study, all of the genotypes fit the Hardy-Weinberg equilibrium expectations (data not shown). The frequency of the $14 \mathrm{bp} \mathrm{In/Del}$ polymorphism was 31.9 and $68.1 \%$ in the HPV16 group; 38.5 and $61.5 \%$ in the HPV18 group; and 29.2 and $70.8 \%$ in the control group, respectively. We found that the $14 \mathrm{bp} \mathrm{In} / \mathrm{Del}$ alleles and genotypes were not associated with a susceptibility to HPV16 infections. However, the frequency of the allele, $14 \mathrm{bp} \mathrm{Del}$, was significantly decreased in the HPV18 group, compared with the control group $(61.5 \%$ vs $70.8 \%$, OR $=0.66 ; P=0.015)$; similar significance was observed for the genotype, Del/Del (35.4\% vs $48.7 \%$, OR = $0.58, P=0.019$ ) (Table 2).

Moreover, the frequency of the $+3142 \mathrm{C} / \mathrm{G}$ polymorphism was 41.9 and $58.1 \%$ in the HPV16 group; 27.3 and $72.7 \%$ in the HPV18 group; and 43.0 and $57.0 \%$ in control group, respectively. We found that the $+3142 C / G$ alleles and genotypes were not associated with a susceptibility to HPV16 infections. However, the frequency of the allele, $+3142 G$, was significantly increased in the HPV18 group, compared with the control group $(72.7 \%$ vs $57.0 \%, \mathrm{OR}=2.01, P<0.001)$; similar significance was observed for the genotype, $+3142 G / G(51.5 \%$ vs $35.1 \%$, $\mathrm{OR}=1.96, P=0.004)$. Furthermore, the frequency of the haplotype, $14 \mathrm{bp} \mathrm{Del/}+3142 \mathrm{C}$, was also significantly decreased in the HPV18 group (27.3\% vs $43.0 \%$, OR $=0.50$, $P<0.001$ ) (Table 2). These results show that the $H L A-G$ polymorphism (alleles $14 \mathrm{bp}$ In and $+3142 G$ ) is a susceptibility factor for HPV18 infections.

\section{HLA-G 3' UTR polymorphism association with the progression of HPV18-related cervical lesions}

To test the effect of the HLA-G polymorphism on the progression of cervical lesions from CIN1 to cervical cancer in the HPV18 group, we carried out a separate analysis restricted to normal histology, CIN1 and CIN2 + . When compared with the control group, the frequency was dramatically increased in CIN1 subgroup for the allele, $+3142 G(81.8 \%$ vs $57.0 \%, O R=3.39,95 \% \mathrm{CI}$ : $1.19-9.65, P=0.022)$, and the genotype, $+3142 G / G$ (63.6\% vs $35.1 \%, \quad \mathrm{OR}=3.23,95 \% \mathrm{CI}: 0.96-10.83, P=$ 0.056). Furthermore, we found that the frequency of the

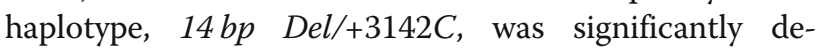
creased in CIN1 $(18.1 \%$ vs $43.0 \%, \mathrm{OR}=0.29,95 \% \mathrm{CI}$ : $0.10-0.84, P=0.022)$. When the $\mathrm{CIN} 2+$ subgroup was compared with the control group, the frequency of the genotype, $14 \mathrm{bp} I n / I n$, was also significantly increased (33.3\% vs $7.0 \%$, OR $=6.62, P=0.018$ ) (Table 3 ). These results show that the $H L A-G$ polymorphism (alleles $14 \mathrm{bp}$ In and $+3142 G)$ is associated with the progression of HPV18-related cervical lesions.
We then performed logistic regression models to evaluate the influence of HLA-G polymorphisms on the susceptibility to HPV18-related cervical lesions (adjusted for age). No significant associations were observed when the HPV18 group was subdivided into CIN1 and CIN2+. Notably, the age of patients in the CIN2+ subgroup was much older than in the CIN1 subgroup (50.2 \pm 12.3 vs. $40.5 \pm 10.1$ ), which shows that the HPV18 genotype does require a longer time period to become carcinogenic and lead to a progression from low-grade to high-grade cervical lesions.

\section{HLA-G expression association with the progression of HPV18-related cervical lesions}

To investigate the association of HLA-G protein expression with HPV18-related cervical carcinogenesis, we analyzed 26, case-matched, HPV18-related, cervical tissues by IHC, with anti-HLA-G mAb 4H84 for HLA-G expression (2 ADC, 3 CIN3, 1 CIN2, 11 CIN1, and 9 normal tissues). We found that $66.7 \%(4 / 6)$ of $\mathrm{CIN} 2+$ lesions were classified as HLA-G positive, while only $18.2 \%(2 / 11)$ of CIN1 lesions were HLA-G positive. HLA-G staining yielded a negative result in normal tissues.

A strong and uniform HLA-G staining was observed in basal cells of the epithelium, where cells hollowed out by HPV were observed (Fig. 1A and B). HLA-G protein is diffusely expressed in cytoplasm and cell membrane. A higher frequency of HLA-G staining was observed in squamous epithelial cells among high-grade CIN lesions (Fig. 1C - E). Overall, positive for HLA-G expression increased from CIN1 to CIN2/3 lesions and was highest in patients with ADC; however, a significant association with the polymorphisms of HLA-G was not observed. The limited sample size of case-matched, HPV18-related, cervical tissues examined in this study may have influenced the results.

\section{Discussion}

Persistent infection with oncogenic HPV types, especially HPV16 and HPV18, has a strong association with cervical cancer $[15,16]$. This conclusion was also confirmed in our previous epidemiological study, where we found that the natural prevalence of HPV16 was 3.1\% in the general population, but increased significantly in CIN2 (31.6\%) and CIN3 (47.9\%) lesions, reaching 60.6\% in ICC. We observed a similar distribution pattern for HPV18. The natural prevalence of HPV18 was $1.5 \%$ in the general population, and increased steeply, to $5.6 \%$, in CIN2+ lesions [11]. However, this is far lower than that the $13.0 \%$ figure reported in a global meta-analysis [17]. Moreover, our previous findings also indicated that HLA-G expression was associated with disease progression in cervical cancer [9]. Mounting evidence has 
Table 2 Distribution of HLA-G allele, genotype and haplotype in controls and patients, stratified according to HPV type

\begin{tabular}{|c|c|c|c|c|c|}
\hline \multirow{3}{*}{ Alleles } & \multirow{3}{*}{$\begin{array}{l}\text { Control } \\
\text { group }\end{array}$} & \multicolumn{4}{|c|}{ Patient group } \\
\hline & & \multicolumn{2}{|c|}{ HPV 16 group } & \multicolumn{2}{|c|}{ HPV 18 group } \\
\hline & & $n(\%)$ & $\mathrm{OR}(95 \% \mathrm{Cl})$ & $n(\%)$ & $\mathrm{OR}(95 \% \mathrm{Cl})$ \\
\hline \multicolumn{6}{|c|}{14 bp In/Del } \\
\hline $\ln$ & 108(29.2) & 83(31.9) & $1.14(0.81-1.60)$ & $100(38.5)$ & $1.52(1.08-2.12)^{\mathrm{a}}$ \\
\hline Del & 262(70.8) & $177(68.1)$ & $0.88(0.62-1.24)$ & $160(61.5)$ & $0.66(0.47-0.92)^{a}$ \\
\hline$n$ & 370 & 260 & & 260 & \\
\hline \multicolumn{6}{|c|}{ +3142 C/G } \\
\hline$C$ & 159(43.0) & 109(41.9) & $0.96(0.69-1.32)$ & $71(27.3)$ & $0.50(0.36-0.70)^{b}$ \\
\hline$G$ & $211(57.0)$ & $151(58.1)$ & $1.04(0.75-1.44)$ & 189(72.7) & $2.01(1.43-2.82)^{b}$ \\
\hline$n$ & 370 & 260 & & 260 & \\
\hline \multicolumn{6}{|c|}{ Genotypes } \\
\hline \multicolumn{6}{|c|}{14 bp In/Del } \\
\hline $\ln / \ln$ & $13(7.0)$ & 13(10.0) & $1.47(0.66-3.28)$ & $16(12.3)$ & $1.86(0.87-3.98)$ \\
\hline In/Del & $82(44.3)$ & $57(43.8)$ & $0.98(0.62-1.54)$ & $68(52.3)$ & $1.38(0.88-2.16)$ \\
\hline Del/Del & $90(48.7)$ & $60(46.2)$ & $0.90(0.57-1.42)$ & $46(35.4)$ & $0.58(0.36-0.92)^{c}$ \\
\hline$n$ & 185 & 130 & & 130 & \\
\hline \multicolumn{6}{|c|}{$+3142 \mathrm{C} / \mathrm{G}$} \\
\hline$C / C$ & $39(21.1)$ & $25(19.2)$ & $0.89(0.51-1.56)$ & $8(6.2)$ & $0.25(0.12-0.52)^{d}$ \\
\hline$C / G$ & $81(43.8)$ & $59(45.4)$ & $1.07(0.68-1.68)$ & $55(42.3)$ & $0.94(0.60-1.48)$ \\
\hline$G / G$ & $65(35.1)$ & $46(35.4)$ & $1.01(0.63-1.62)$ & $67(51.5)$ & $1.96(1.24-3.10)^{\mathrm{e}}$ \\
\hline$n$ & 185 & 130 & & 130 & \\
\hline \multicolumn{6}{|c|}{ Haplotypes } \\
\hline $\ln / G$ & 108(29.2) & $83(31.9)$ & $1.14(0.81-1.60)$ & $100(38.5)$ & $1.52(1.08-2.12)^{f}$ \\
\hline $\mathrm{Del} / \mathrm{G}$ & 103(27.8) & $68(26.2)$ & $0.92(0.64-1.31)$ & $89(34.2)$ & $1.35(0.96-1.90)$ \\
\hline $\mathrm{Del} / \mathrm{C}$ & $159(43.0)$ & 109(41.9) & $0.96(0.69-1.32)$ & $71(27.3)$ & $0.50(0.35-0.70)^{9}$ \\
\hline$n$ & 370 & 260 & & 260 & \\
\hline
\end{tabular}

Significant association is highlighted in bold

$C l$ confidence interval, $O R$ odds ratio

${ }^{\mathrm{a}} X^{2}=5.94, P=0.015$

${ }^{b} X^{2}=16.17, P=0.000$

${ }^{2} X^{2}=5.48, P=0.019$

${ }^{d} x^{2}=13.40, P=0.000$

${ }^{e} X^{2}=8.44, P=0.004$

${ }^{\mathrm{f}} \mathrm{X}^{2}=5.94, P=0.015$

${ }^{9} X^{2}=16.17, P=0.000$

shown that, besides oncogenic HPV types, other risk factors may be associated with the progression of cervical cancer, as well. These risk factors include aberrant expression of HLA-G $[9,18-20]$, polymorphisms of the HLA-G gene [10, 21-23], smoking habits and immune suppression [24].

HLA-G is a natural, tolerogenic molecule, with well-characterized immunoinhibitory properties. Its expression in cervical cancer cells may enable them to escape immunosurveillance [5, 9]. Our previous study revealed the involvement of the HLA-G molecule in the susceptibility to and outcome of HPV infections [10].

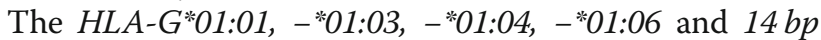
In alleles were associated with an increased risk of HPV infection acquisition and persistence, which may potentially impact the development of cervical lesions [10, 22, 23, 25-27]. The HLA-G $14 \mathrm{bp} \mathrm{Del}$ and $+3142 \mathrm{C}$ alleles seems to confer protection against, instead of being a risk factor for, HPV infections [10, 22, 25-27]. The 14 bp In allele in the $3^{\prime}$ 'UTR of the HLA-G gene is associated with lower sHLA-G plasma levels [28-30]. However, the results obtained were inconclusive and even contradictory, as the HLA-G molecule was observed differentially at either decreased [31] or increased expression levels $[9,18,19,32]$ in cervical cancer tissues. Therefore, the level of HLA-G expression in malignant cells may vary according to the type of cancer. In the present study, we investigated the association of the HLA-G polymorphism and its expression 
Table 3 Distribution of HLA-G allele, genotype and haplotype by disease status

\begin{tabular}{|c|c|c|c|c|c|c|c|}
\hline & \multirow{3}{*}{$\begin{array}{l}\text { Control } \\
\text { group } \\
40.8 \pm 8.0\end{array}$} & \multicolumn{6}{|c|}{ HPV 18 group } \\
\hline & & \multicolumn{2}{|l|}{ Normal } & \multicolumn{2}{|l|}{ CIN 1} & \multicolumn{2}{|l|}{ CIN 2+ } \\
\hline & & \multicolumn{2}{|c|}{$39.1 \pm 8.9$} & \multicolumn{2}{|c|}{$40.5 \pm 10.1$} & \multicolumn{2}{|c|}{$50.2 \pm 12.3$} \\
\hline Alleles & $n(\%)$ & $n(\%)$ & OR(95\% Cl) & $n(\%)$ & $\mathrm{OR}(95 \% \mathrm{Cl})$ & $n(\%)$ & $\mathrm{OR}(95 \% \mathrm{Cl})$ \\
\hline \multicolumn{8}{|l|}{14 bp In/Del } \\
\hline$+14 \mathrm{bp}$ & 108(29.2) & $38(38.0)$ & $1.48(0.94-2.36)$ & $8(36.4)$ & $1.39(0.57-3.39)$ & $6(50.0)$ & 2.43(0.79-7.45) \\
\hline$-14 b p$ & $262(70.8)$ & $62(62.0)$ & $0.67(0.42-1.07)$ & 14(63.6) & $0.72(0.29-1.77)$ & $6(50.0)$ & $0.41(0.13-1.27)$ \\
\hline$n$ & 370 & 100 & & 22 & & 12 & \\
\hline \multicolumn{8}{|l|}{$+3142 C / G$} \\
\hline C & 159(43.0) & 23(23.0) & $0.40(0.24-0.65)^{a}$ & $4(18.2)$ & $0.29(0.10-0.84)^{b}$ & $4(33.3)$ & $0.66(0.20-2.23)$ \\
\hline G & $211(57.0)$ & $77(77.0)$ & $2.52(1.53-4.16)^{a}$ & 18(81.8) & $3.39(1.19-9.65)^{b}$ & $8(66.7)$ & $1.51(0.45-5.06)$ \\
\hline$n$ & 370 & 100 & & 22 & & 12 & \\
\hline \multicolumn{8}{|l|}{ Genotypes } \\
\hline \multicolumn{8}{|l|}{14 bp In/Del } \\
\hline + $14 \mathrm{bp} /+14 \mathrm{bp}$ & $13(7.0)$ & $5(10.0)$ & $1.47(0.50-4.33)$ & $1(9.1)$ & $1.32(0.16-11.14)$ & 2(33.3) & $6.62(1.37-31.40)^{c}$ \\
\hline$+14 b p /-14 b p$ & $82(44.3)$ & $28(56.0)$ & $1.60(0.85-2.99)$ & $6(54.5)$ & $1.51(0.45-5.09)$ & $3(50.0)$ & $1.26(0.25-6.39)$ \\
\hline$-14 b p /-14 b p$ & $90(48.7)$ & 17(34.0) & $0.54(0.28-1.04)$ & $4(36.4)$ & $0.60(0.17-2.11)$ & $1(16.7)$ & $0.21(0.03-1.53)$ \\
\hline$n$ & 185 & 50 & & 11 & & 6 & \\
\hline \multicolumn{8}{|l|}{$+3142 C / G$} \\
\hline $\mathrm{C} / \mathrm{C}$ & $39(21.1)$ & $1(2.0)$ & $0.08(0.02-0.37)^{d}$ & $0(0.0)$ & $0(0.00-0.00)$ & $1(16.7)$ & 0.75(0.09-6.59) \\
\hline$C / G$ & $81(43.8)$ & $21(42.0)$ & $0.93(0.49-1.75)$ & $4(36.4)$ & $0.73(0.21-2.59)$ & 2(33.3) & $0.64(0.12-3.56)$ \\
\hline $\mathrm{G} / \mathrm{G}$ & $65(35.1)$ & $28(56.0)$ & $2.35(1.26-4.40)^{\mathrm{e}}$ & $7(63.6)$ & $3.23(0.96-10.83)$ & $3(50.0)$ & $1.85(0.37-9.24)$ \\
\hline$n$ & 185 & 50 & & 11 & & 6 & \\
\hline \multicolumn{8}{|l|}{ Haplotypes } \\
\hline$+14 \mathrm{bp} / \mathrm{G}$ & 108(29.2) & $38(38.0)$ & $1.49(0.94-2.36)$ & $8(36.4)$ & $1.39(0.57-3.39)$ & $6(50.0)$ & 2.43(0.79-7.45) \\
\hline$-14 \mathrm{bp} / \mathrm{G}$ & 103(27.8) & 39(39.0) & $1.66(1.05-2.62)^{f}$ & $10(45.5)$ & $2.16(0.92-5.07)$ & $2(16.7)$ & $0.52(0.11-2.35)$ \\
\hline$-14 \mathrm{bp} / \mathrm{C}$ & 159(43.0) & $23(23.0)$ & $0.40(0.24-0.65)^{g}$ & $4(18.1)$ & $0.29(0.10-0.84)^{h}$ & $4(33.3)$ & $0.66(0.20-2.23)$ \\
\hline$n$ & 370 & 100 & & 22 & & 12 & \\
\hline
\end{tabular}

Significant association are highlighted in bold

$\mathrm{Cl}$ confidence interval, $O R$ odds ratio

${ }^{\mathrm{a}} \mathrm{X}^{2}=13.23, P=0.000$

${ }^{b} X^{2}=5.25, P=0.022$

$X^{2}=5.53, P=0.018$

${ }^{d} X^{2}=10.15, P=0.001$

${ }^{e} X^{2}=7.17, P=0.007$

${ }^{\mathrm{f}} \mathrm{X}^{2}=4.65, P=0.031$

${ }^{9} X^{2}=13.23, P=0.000$

${ }^{\mathrm{h}} \mathrm{X}^{2}=5.25, P=0.022$

with the development of cervical lesions caused by either HPV16 or HPV18. To the best of our knowledge, this study is the first to explore the potential relationship between the HLA-G molecule and HPV18-related cervical cancer risk. We observed that the HLA-G $14 b p$ In and + $3142 G$ alleles are risk factors for an HPV18 infection and influence the progression of HPV18-related cervical lesions. In addition, HLA-G protein expression increased from CIN1 to CIN2/3 lesions and was highest in patients with ADC; however, a significant association of these lesions with HLA-G polymorphisms was not observed. The limited sample size of case-matched, HPV18-related, cervical tissues examined in this study may have influenced the results.

Expression of the HLA-G protein at different stages and sites of cervical lesions is dependent on a combination of transcription factors, miRNAs, and microenvironmental factors. The aspects of the host's genetic diversities that impact an immune response are likely determine those who are at higher risk for progressing to cervical cancer among infected individuals. The $14 \mathrm{bp}$ In and del alleles alter the set of miRNAs that are able to play a crucial regulatory role by targeting mRNAs for silencing. The $+3142 C / G$ polymorphism, located $167 \mathrm{bp}$ 


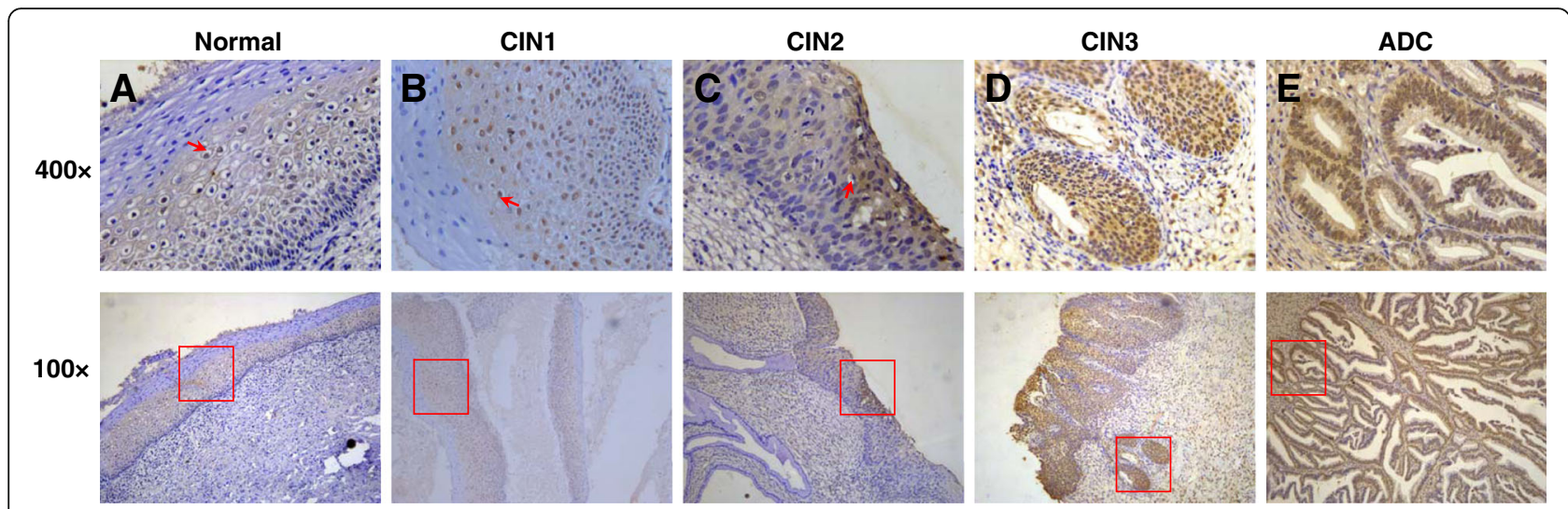

Fig. 1 Immunohistochemical staining of HLA-G expression in cervical lesions. (a) normal cervical tissue. The arrow refer to HPV hollowed out cells; (b) CIN1 lesion. The arrow refer to basal cells of the epithelium; (c) CIN2 lesion; (d) CIN3 lesion. Squamous cell abnormalities involving glands; (e) Adenocarcinoma. HLA-G protein is diffusely expressed in cytoplasm and membrane. Positive for HLA-G expression increased from CIN1 to CIN2/3 lesions and was highest in ADC lesions

downstream from the $14 \mathrm{bp}$ polymorphic site, is also thought to influence miRNA binding. It was demonstrated that the $+3142 G$ allele may influence HLA-G expression by increasing its binding affinity for miRNAs (miR-148a, -148b and -152), result in a downregulation of HLA-G protein expression through mRNA degradation and translation suppression [33-35]. The miR-mediated inhibition of HLA-G was shown to enhance NK cell recognition [34]. Furthermore, the $14 \mathrm{bp}$ In/Del and $+3142 \mathrm{C} / \mathrm{G}$ polymorphisms are in a state of linkage disequilibrium [35, 36]; their combination into haplotypes may be involved in the regulation of HLA-G gene expression $[36,37]$. In our population, three $(14 \mathrm{bp}$ In/+3142G, $14 \mathrm{bp} \mathrm{Del/+3142G,} 14 \mathrm{bp} \mathrm{Del/+3142C)}$ of four possible haplotypes (14 bp In/+3142G, 14 bp Del/ +3142G, $14 \mathrm{bp} \quad \mathrm{In} /+3142 \mathrm{C}, 14 \mathrm{bp} \quad \mathrm{Del} /+3142 \mathrm{C})$ were found (Table 2). Similar results were reported by Silva et al. [27] in Brazil and Ferguson et al. [22] in Canada, where a significantly increased cervical cancer risk was found to be associated with the $14 \mathrm{bp} I \mathrm{In} /+3142 \mathrm{G}$ haplotype. However, inconsistent results were obtained by Bortolotti et al. [21] in Italy and Yang et al. [38] in Taiwan, where a significantly decreased cancer risk was found to be associated with the $14 \mathrm{bp} I n /+3142 \mathrm{G}$ haplotype. The discrepancy between the results of these studies and ours may be due to differing ethnicities, ages, sample sizes, genetic diversities, risk factors associated with lifestyle, and environmental factors.

In this study, we investigated the total HLA-G expression in HPV18-related cervical tissues with anti-HLA-G mAb $4 \mathrm{H} 84$, by IHC. We found that the HLA-G protein was detected in the basal cells of the epithelium, which is the initial site of HPV infections. A higher frequency of HLA-G staining was observed in squamous epithelial cells among high-grade CIN lesions. However, a significant association between lesions and the polymorphisms of HLA-G was not observed. The largest limitation of our study was sample size. Since the time between HPV infections and CIN3 lesions was calculated to be 7-15 years post-infection [39], this results in a limited sample size of case-matched, HPV18-related, cervical tissues in this study (which may have affected the outcome). Due to the small sample size, the statistical analyses involving the levels of HLA-G protein expression and six cases of HPV18-related high-grade cervical lesions, were hindered. Our data demonstrated that HLA-G expression progressively increased from CIN 1 to CIN2/3 lesions and was highest in patients with malignant cervical lesions. These results were consistent with those of previous studies, which revealed that HLA-G is selectively expressed in cervical tissues, is associated with HPV infections $[19,31]$ and is associated with cervical lesion progression [9, 18, 32]. Guimarães et al. [31] reported that the HLA-G5 isoform (with mAb 5A6G7) was detected in 25 out of 74 cervical cancer tissues, but not in all HPV-related cases. Moreover, Dong et al. [19] found that HLA-G expression was significantly higher in CIN and cervical cancer lesions infected with HPV16/18 than in HPV-negative patients. In our study, all of the patients were infected with HPV18, and it is possible that HPV could contribute to HLA-G expression. Indeed, the mechanisms of HPV involvment in the modulation of HLA-G expression among different types of cervical cancer remain to be determined. This association may be influenced by the tumor microenvironment, as well as by the pathogenesis underlying the malignant transformation of the cells, such as transcriptional regulation, epigenetic modifications, and cytokine profiles.

\section{Conclusion}

Our results support that the $H L A-G 14 \mathrm{bp}$ In and + $3142 G$ alleles are risk factors for HPV18 infections and 
influence the progression of HPV18-related cervical lesions in the Chinese Han population. Our findings suggest that HLA-G-driven immune mechanisms play an important role in the progression from low-grade to high-grade lesions in cervical disease. However, the clinical relevance of HLA-G in cervical cancer needs to be further explored.

\section{Acknowledgements}

We appreciate participants included the study, and pathologists and gynecologist in our hospital for assistance.

\section{Author contributions \\ Designed the experiments: WHY HHX. HLA-G and HPV genotyping: AFL HHX. Cytology testing and pathological diagnosis: HHZ XZ. Immunohistochemistry and Staining evaluation: AFL XZ QYH. Performed statistical analysis and drafted the manuscript: HHX WHY. All authors read and approved the final manuscript.}

\section{Ethical approval}

This study was approved by the Institutional Medical Ethics Review Board of Taizhou Hospital of Zhejiang Province. All of the participants provided written, informed consent to the study.

\section{Funding}

This work was supported by grants from the Science and Technology Bureau of Zhejiang Province (2016C33231), the Health Bureau of Zhejiang Province (2015KYB438), the National Natural Science Foundation of China (31370920, 81372247)

\section{Availability of data and materials}

All data generated or analysed during this study are included in this published in this article. The datasets used and/or analyzed during the current study are available from the corresponding author on reasonable request.

\section{Consent for publication}

We all agreed to submit our manuscript "Association of HLA-G 3' UTR polymorphism and expression with the progression of cervical lesions in human papillomavirus 18 infections" to Infectious Agents and Cancer. This manuscript has not been submitted to elsewhere.

\section{Competing interests}

The authors declare no conflict of interests.

\section{Publisher's Note}

Springer Nature remains neutral with regard to jurisdictional claims in published maps and institutional affiliations.

\section{Author details}

${ }^{1}$ Medical Research Center, Taizhou Hospital of Zhejiang Province, Wenzhou Medical University, Linhai, Zhejiang, China. '2Laboratory of Gynecologic Oncology, Taizhou Hospital of Zhejiang Province, Wenzhou Medical University, Linhai, Zhejiang, China. ${ }^{3}$ Human Tissue Bank, Taizhou Hospital of Zhejiang Province, Wenzhou Medical University, Linhai, Zhejiang, China. ${ }^{4}$ Department of Pathology, Taizhou Hospital of Zhejiang Province, Wenzhou Medical University, Linhai, Zhejiang, China.

Received: 27 October 2018 Accepted: 20 December 2018

Published online: 29 December 2018

\section{References}

1. Torre LA, Bray F, Siegel RL, Ferlay J, Lortet-Tieulent J, Jemal A. Global cancer statistics, 2012. CA Cancer J Clin. 2015;65:87-108.

2. Crosbie EJ, Einstein MH, Franceschi S, Kitchener HC. Human papillomavirus and cervical cancer. Lancet. 2013;382:889-99.

3. Sasagawa T, Takagi H, Makinoda S. Immune responses against human papillomavirus (HPV) infection and evasion of host defense in cervical cancer. J Infect Chemother. 2012;18:807-15.
4. Carosella ED, HoWangYin KY, Favier B, LeMaoult J. HLA-G-dependent suppressor cells: diverse by nature, function, and significance. Hum Immunol. 2008;69:700-7.

5. Yan WH. HLA-G Expression in Cancers: Potential Role in Diagnosis, Prognosis and Therapy. Endocr Metab Immune Disord Drug Targets. 2011;11:76-89.

6. Donadi EA, Castelli EC, Arnaiz-Villena A, Roger M, Rey D, Moreau P. Implications of the polymorphism of HLA-G on its function, regulation, evolution and disease association. Cell Mol Life Sci. 2011;68:369-95.

7. Rousseau P, Le Discorde M, Mouillot G, Marcou C, Carosella ED, Moreau P. The $14 \mathrm{bp}$ deletion-insertion polymorphism in the $3^{\prime}$ UT region of the HLAG gene influences HLA-G mRNA stability. Hum Immunol. 2003;64:1005-10.

8. Veit TD, Chies JA. Tolerance versus immune response-microRNAs as important elements in the regulation of the HLA-G gene expression. Transpl Immunol. 2009;20:229-31.

9. Li XJ, Zhang X, Lin A, Ruan YY, Yan WH. Human leukocyte antigen-G (HLA$\mathrm{G})$ expression in cervical cancer lesions is associated with disease progression. Hum Immunol. 2012;73:946-9.

10. $\mathrm{Xu} \mathrm{HH}$, Shi WW, Lin A, Yan WH. HLA-G 3' untranslated region polymorphisms influence the susceptibility for human papillomavirus infection. Tissue Antigens. 2014;84:216-22.

11. Xu H, Lin A, Shao X, Shi W, Zhang Y, Yan W. Diagnostic accuracy of high-risk HPV genotyping in women with high-grade cervical lesions: evidence for improving the cervical cancer screening strategy in China. Oncotarget. 2016; 7:83775-83.

12. Jiang HL, Zhu HH, Zhou LF, Chen F, Chen Z. Genotyping of human papillomavirus in cervical lesions by L1 consensus PCR and the Luminex xMAP system. J Med Microbiol. 2006;55:715-20.

13. Chew SF, Kanaan C, Tait BD. HLA expression and cancer--14th IHIWS immunohistochemistry quality control exercise exchange results. Tissue Antigens. 2007;69(Suppl 1):248-51.

14. Xu HH, Zheng LZ, Lin AF, Dong SS, Chai ZY, Yan WH. Human papillomavirus (HPV) 18 genetic variants and cervical cancer risk in Taizhou area, China. Gene. 2018;647:192-7

15. Clifford GM, Smith JS, Aguado T, Franceschi S. Comparison of HPV type distribution in high-grade cervical lesions and cervical cancer: a metaanalysis. Br J Cancer. 2003:89:101-5.

16. Schiffman M, Wentzensen N. Human papillomavirus infection and the multistage carcinogenesis of cervical cancer. Cancer Epidemiol Biomark Prev. 2013;22:53-60

17. Guan P, Howell-Jones R, Li N, Bruni L, de Sanjosé S, Franceschi S, et al. Human papillomavirus types in 115,789 HPV-positive women: a metaanalysis from cervical infectio to cancer. Int J Cancer. 2012;131:2349-59.

18. Zheng N, Wang CX, Zhang X, Du LT, Zhang J, Kan SF, et al. Up-regulation of HLA-G expression in cervical premalignant and malignant lesions. Tissue Antigens. 2011;77:218-24.

19. Dong DD, Yang H, Li K, Xu G, Song LH, Fan XL, et al. Human leukocyte antigen-G (HLA-G) expression in cervical lesions: association with cancer progression, HPV 16/18 infection, and host immune response. Reprod Sci. 2010:17:718-23.

20. Gimenes F, Teixeira JJ, de Abreu AL, Souza RP, Pereira MW, da Silva VR, et al. Human leukocyte antigen (HLA)-G and cervical cancer immunoediting: a candidate molecule for therapeutic intervention and prognostic biomarker? Biochim Biophys Acta. 1846;2014:576-89.

21. Bortolotti D, Gentili V, Rotola A, Di Luca D, Rizzo R. Implication of HLA-G 3' untranslated region polymorphisms in human papillomavirus infection. Tissue Antigens. 2014;83:113-8.

22. Ferguson $\mathrm{R}$, Ramanakumar AV, Koushik A, Coutlée F, Franco E, Roger M, et al. Human leukocyte antigen $G$ polymorphism is associated with an increased risk of invasive cancer of the uterine cervix. Int J Cancer. 2012;131: E312-9.

23. Simoes RT, Goncalves MA, Castelli EC, Júnior CM, Bettini JS, Discorde ML, et al. HLA-G polymorphisms in women with squamous intraepithelial lesions harboring human papillomavirus. Mod Pathol. 2009;22:1075-82.

24. Gadducci A, Barsotti C, Cosio S, Domenici L, Riccardo GA. Smoking habit, immune suppression, oral contraceptive use, and hormone replacement therapy use and cervical carcinogenesis: a review of the literature. Gynecol Endocrinol. 2011;27:597-604.

25. Smith MA, Tellier PP, Roger M, Coutlée F, Franco EL, Richardson H. Determinants of human papillomavirus coinfections among Montreal university students: the influence of behavioral and biologic factors. Cancer Epidemiol Biomark Prev. 2014;23:812-22. 
26. Metcalfe S, Roger M, Faucher MC, Coutlée F, Franco EL, Brassard P. The association between human leukocyte antigen (HLA)-G polymorphisms and human papillomavirus (HPV) infection in Inuit women of northern Quebec. Hum Immunol. 2013;74:1610-5.

27. Silva ID, Muniz YC, Sousa MC, Silva KR, Castelli EC, Filho JC, et al. HLA-G $3^{\prime} U T R$ polymorphisms in high grade and invasive cervico-vaginal cancer. Hum Immunol. 2013;74:452-8.

28. Chen $X Y$, Yan $W H$, Lin $A, X u H H$, Zhang JG, Wang $X X$. The 14 bp deletion polymorphisms in HLA-G gene play an important role in the expression of soluble HLA-G in plasma. Tissue Antigens. 2008;72:335-41.

29. Hviid TV, Rizzo R, Christiansen OB, Melchiorri L, Lindhard A, Baricordi OR. HLA-G and IL-10 in serum in relation to HLA-G genotype and polymorphisms. Immunogenetics. 2004;56:135-41.

30. Rizzo R, Hviid TV, Govoni M, Padovan M, Rubini M, Melchiorri L, et al. HLA-G genotype and HLA-G expression in systemic lupus erythematosus: HLA-G as a putative susceptibility gene in systemic lupus erythematosus. Tissue Antigens. 2008;71:520-9.

31. Guimarães MC, Soares CP, Donadi EA, Derchain SF, Andrade LA, Silva TG, et al. Low expression of human histocompatibility soluble leukocyte antigen-G (HLA-G5) in invasivecervical cancer with and without metastasis, associated with papilloma virus (HPV). J Histochem Cytochem. 2010;58:405-11.

32. Rodríguez JA, Galeano L, Palacios DM, Gómez C, Serrano ML, Bravo MM, et al. Altered HLA class I and HLA-G expression is associated with IL-10 expression in patients with cervical cancer. Pathobiology. 2012;79:72-83.

33. Celsi F, Catamo E, Kleiner G, Tricarico PM, Vuch J, Crovella S. HLA-G/C, miRNAs, and their role in HIV infection and replication. Biomed Res Int. 2013;2013:693643

34. Jasinskibergner S, Hartmann A, Spath V, Huettelmaier S, Braun J, Braun J, et al. HLA-G-specific microRNAs a novel approach for targeting tumors. Immunother Cancer. 2013;1:P174.

35. Tan Z, Randall G, Fan J, Camoretti-Mercado B, Brockman-Schneider R, Pan L, et al. Allele-specific targeting of microRNAs to HLA-G and risk of asthma. Am J Hum Genet. 2007;81:829-34.

36. Castelli EC, Mendes-Junior CT, Deghaide NH, de Albuquerque RS, Muniz YC, Simões RT, et al. The genetic structure of 3'untranslated region of the HLA$\mathrm{G}$ gene: polymorphisms and haplotypes. Genes Immun. 2010;11:134-41.

37. Castelli EC, Mendes-Junior CT, Veiga-Castelli LC, Roger M, Moreau P, Donadi EA. A comprehensive study of polymorphic sites along the HLA-G gene: implication for generegulation and evolution. Mol Biol Evol. 2011;28:3069-86.

38. Yang YC, Chang TY, Chen TC, Lin WS, Chang SC, Lee YJ. Human leucocyte antigen-G polymorphisms are associated with cervical squamous cell carcinoma risk in Taiwanese women. Eur J Cancer. 2014;50:469-74.

39. Moscicki AB, Schiffman M, Kjaer S, Villa LL. Chapter 5: updating the natural history of HPV and anogenital cancer. Vaccine. 2006;24(Suppl 3):S3/42-51.

Ready to submit your research? Choose BMC and benefit from:

- fast, convenient online submission

- thorough peer review by experienced researchers in your field

- rapid publication on acceptance

- support for research data, including large and complex data types

- gold Open Access which fosters wider collaboration and increased citations

- maximum visibility for your research: over $100 \mathrm{M}$ website views per year

At BMC, research is always in progress.

Learn more biomedcentral.com/submissions 